\title{
Mechanics of hollow concrete block masonry prisms under compression: Review and prospects
}

\author{
Gihad Mohamad ${ }^{\mathrm{a}, *}$, Paulo B. Lourenço ${ }^{\text {a }}$, Humberto R. Roman ${ }^{\mathrm{b}}$

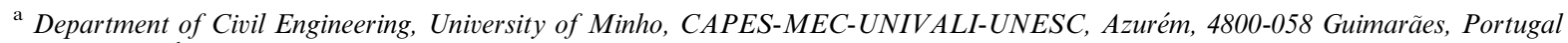 \\ ${ }^{\mathrm{b}}$ Civil Engineering Department of Federal University of Santa Catarina, 88049-900 Florianópolis, Brazil
}

Received 12 December 2005; received in revised form 31 October 2006; accepted 11 November 2006

Available online 27 December 2006

\begin{abstract}
The aim of this work is to critically assess the mechanical properties of hollow concrete masonry using experimental results from prisms constructed with blocks of two different strengths and four types of mortar. A key conclusion is that mortar is mostly responsible for the non-linear behavior of masonry. Moreover, a strongly non-linear relationship between masonry elasticity modulus and compressive strength is found, which contradicts the simple linear relation proposed by Eurocode 6 [CEN. Eurocode 6: Design of masonry structures - Part 1 - Common rules for reinforced and unreinforced masonry structures. EN-1996-1-1; 2005.]. The porosity of mortar and the state of stress that mortar undergoes in the process of compressive loading can be responsible for changes in the mechanical properties, such as elasticity modulus and Poisson's ratio. Finally, different types of mortars induce different failure modes in the masonry prisms and there is clear evidence that the failure of hollow concrete masonry starts after onset of mortar crushing. In order to better reproduce the observed experimental behavior, a tentative model for the mortar Poisson's ratio variation upon loading is also presented.
\end{abstract}

(c) 2006 Elsevier Ltd. All rights reserved.

Keywords: Stress-strain diagram; Elasticity modulus; Non-linear behavior; Lateral deformation; Failure modes; Poisson's ratio model

\section{Introduction}

The compressive behavior of masonry is of crucial importance for design and safety assessment purposes, since masonry structures are primarily stressed in compression. These values can be obtained from tests on small assemblages or tests on the components. The testing methods vary considerably and depend of the compressive strength of block and mortar. The present approach from codes, e.g. Eurocode 6 [1], is to make the compressive strength of the masonry composite to depend from the compressive strength of the masonry components (unit and mortar). This empirical approach is obviously conservative and results from a lower envelope of a large set of experimental data, meaning that the compressive strength

\footnotetext{
${ }^{*}$ Corresponding author. Tel.: +351 253510 200; fax: +351 253510217 . E-mail address: gihad@civil.uminho.pt (G. Mohamad).
}

of masonry can be severely underestimated. The alternative solution today is to carry out a series of tests in expensive wallets, which is hardly feasible for all possible masonry materials.

Atkinson et al. [2] state that the prediction of compressive strength and deformation characteristics of full scale masonry based on compressive tests of stack-bond masonry prism and the interpretation of the results of prism tests have a significant influence on the allowable stress and stiffness used in masonry design. Obviously, besides the strength another relevant parameter for design is the stress-strain relationship. In particular, the elasticity modulus is a mechanical property influenced by different factors. Here, it is noted that the elasticity modulus of masonry as a composite system includes the effect of the components, namely mortar and unit. Due to the periodic nature of masonry and the fact that most of the deformation is usually concentrated in the units, measurements are often made between plates, even if the measurements 
should be made at mid-height of the units. Relevant factors affecting the effective elasticity modulus of masonry are the large scatter of experimental tests, the compressive strength of the unit, the type of the unit (hollow or solid), the compressive strength of mortar, the state of stress developed during loading, testing technique and construction details. Eurocode 6 [1] states that, in the absence of experimental results, the secant elasticity modulus can be obtained from $E_{\text {mas }}=k \cdot f_{\mathrm{kmas}}$. The recommended value of $k$ is equal to 1000 , independently of the unit geometry, the mortar type or the joint thickness. This kind of relationship would give only an approximate estimate of the elastic modulus. To compare this rule with experimental results, the model of Knutson [3] is adopted to predict the stress-strain relationship.

Cheema and Klingner [4] described the failure criterion curve for hollow prisms using the modular ratio between mortar/block and the failure type (by mortar crushing and transverse block splitting). Material non-linearity was accounted for by using secant modulus, and the strength of constituent materials was computed considering the effects of multiaxial stresses.

An experimental investigation on blockwork masonry prisms was conducted by Khalaf et al. [5,6] to study the effect of different materials on the compressive strength. The conclusion of this work is that an increase of mortar strength of ungrouted prisms by $188 \%$ and $72 \%$ produced only an increase in the prism strength of about $20 \%$.

An experimental investigation was conducted by Vermeltfoort [7] to study the brick-mortar interactions for more accurate explanation of the behavior of masonry when submitted to compressive loading. Vermeltfoort [7] concluded that further research is required for Poisson's ratio of masonry controlling the lateral deformation of specimens. Poisson's ratios are also essential in numerical simulations.

It is noted that most experimental results available in the international literature address hollow concrete grouted masonry, whereas the focus here is ungrouted masonry. The main objective of this investigation is to understand the axial and lateral displacement capacity of concrete hollow block-masonry prisms, considering the influences of varying block-mortar strength combinations. At present, a complete understanding of the mechanisms involved in the deformation and failure of compressed masonry is not possible and it is believed that the development of a theoretical model of universal application is a rather hard task, because of the multiples factors that influence the behavior of brittle materials loaded in compression.

The paper addresses different relevant issues for the discussion of the mechanics of hollow concrete block masonry under compression, namely the shape of the stress-strain diagram, the deformation properties, the lateral deformations of the block, the failure modes and the need of an adequate effective Poisson's ratio model for the mortar. In particular, it is advocated that the failure mechanism of masonry depends on the difference of Poisson's ratio between unit and mortar and their mutual interaction on the interface of both materials.

\section{Shape of the stress-strain diagram for the masonry composite}

Knutson [3] proposed a non-linear shape for stressstrain diagram $\sigma-\varepsilon$ of masonry, whereas Atkinson et al. [2] concluded that there are three typical types of behavior in stress-strain diagrams, namely brittle, ductile and bilinear, depending on the type of mortar and confining stresses.

The elasticity modulus, usually adopted as the measure of stiffness, represents either a secant or tangent modulus, being the latter given by

$E_{\mathrm{t}}=\mathrm{d} \sigma / \mathrm{d} \varepsilon$

The tangent elasticity modulus $E_{\mathrm{t}}$ can be used as an approximation of the relation between stress and strain in the neighborhood of a given point. Knutson [3] reports that Ritter suggests adopting the following formula for the tangent modulus of elasticity $E_{\mathrm{t}}$

$E_{\mathrm{t}}=E_{0}\left(1-\sigma / f_{\mathrm{c}}\right)$

as a function of the initial tangent elasticity modulus $E_{0}$ and the ratio between the normal stress $\sigma$ and the masonry compressive strength $f_{\text {c. }}$ Introducing Eq. (2) in Eq. (1), integrating and rearranging, it is possible to obtain:

$\varepsilon=\int \frac{1}{E_{0} \cdot\left(1-\frac{\sigma}{f_{\mathrm{c}}}\right)} \cdot \mathrm{d} \sigma$

The solution of Eq. (3), hereby denoted as Ritter curve, is a logarithmic relation between two non-dimensional values, namely the normalized strain $K r \cdot \varepsilon$ and the normalized stress $\sigma / \mathrm{f}_{\mathrm{c}}$, given by

$K r \cdot \varepsilon=-\ln \left(1-\frac{\sigma}{f_{\mathrm{c}}}\right)$

where $K r=E_{0} / f_{\mathrm{c}}$ is the so-called Ritter constant, which for concrete assumes a value of 1000 .

Knutson [3] evaluated the stress-strain diagrams for various masonry materials and showed that they can be cast into a mathematical form. The model aims at representing the complexity of material assembly and requires shape and materials parameters. The experimental masonry strain-stress diagram for different combinations of mortar and brick (three solid and one hollow) are shown in Fig. 1. This author concluded that the stress-strain relationship could be approximated through:

$$
\begin{aligned}
& \varepsilon=-\frac{f_{\mathrm{c}}}{E_{0}} \ln \left(1-\frac{\sigma}{f_{\mathrm{c}}}\right), \quad \text { if } \sigma / f_{\mathrm{c}} \leqslant 0.75, \text { Ritter curve } \\
& \varepsilon=-4 \frac{f_{\mathrm{c}}}{E_{0}}\left(0.403-\frac{\sigma}{f_{\mathrm{c}}}\right), \quad \text { if } \sigma / f_{\mathrm{c}}>0.75, \text { Ritter curve correction }
\end{aligned}
$$




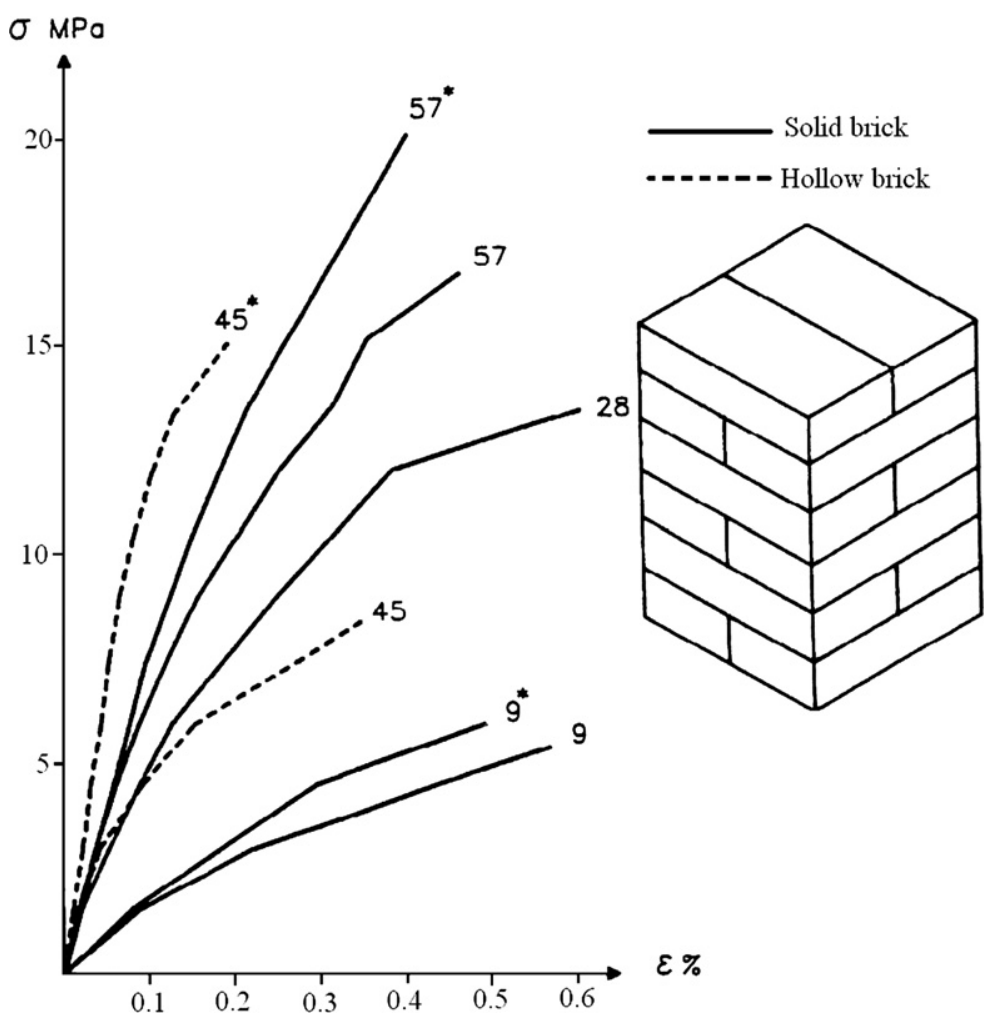

Fig. 1. Stress-strain diagrams of masonry under compression [3]. Numbers indicate brick strength and $*$ indicates stronger mortar.

It is also clear from Fig. 1 that the strain-stress diagrams are significantly different as a result of the unit type and mortar. The normalized stress-strain relation obtained using Eqs. (5) and (6) are given in Fig. 2. The normalized curves show a reasonable agreement with the proposed formulas, except for higher normalized stress values, as $\sigma / f_{\mathrm{c}} \rightarrow 1.0$, then $K r \cdot \varepsilon \rightarrow \infty$.

According to Knutson [3], the results show that masonry built with hollow blocks and weak mortar may not be treated as the others, i.e., the normalized strain should be multiplied by a factor 0.7 . Only using this correction, the stress vs. strain diagram would adequately represent the experimental results. The conclusion of Knutson [3] is that, independently of the material used, it is possible to use the standard stress-strain diagram, suggesting a diagram identical to Ritter's curve for stresses $\sigma \leqslant 0.75 \cdot f_{\mathrm{c}}$ (Eq. (5)) and adopting a linear correction for the Ritter's curve for $\sigma>0.75 \cdot f_{\mathrm{c}}$ (Eq. (6)). But the key issue here is that hollow blocks and weak mortar have stress-strain diagrams different from the other masonry combinations.

\section{Deformation properties for the masonry composite}

Experimental tests in masonry prisms were carried at the Federal University of Santa Catarina, Brazil, to determine the response of masonry subjected to compression [8-10]. Prisms made of hollow concrete blocks and a wide range of mortar strengths have been adopted in this study. The prisms were built using four different mortars types, low strength (1:1:6 and 1:2:9), medium strength (1:0.5:4.5) and high strength (1:0.25:3), as indicated in the standards ASTM C-270 [11] and BS-5628 [12]. Here, c:l:s, give the cement:lime:sand compositions in volume. For each type of mortar six steel-molded cylinders were cast with $50 \mathrm{~mm}$ of diameter and $100 \mathrm{~mm}$ of height to determine the compressive strength of mortar according to NBR 13279 [13]. The prisms were capped with a thin layer of cement paste. The loading rates used for testing the prism were $0.05 \mathrm{~N} / \mathrm{mm}^{2} / \mathrm{s}$. The axial and lateral deformations in the prisms were measured in 20 locations over a gauge length of $200 \mathrm{~mm}$ using Demec-gauges. All elasticity modulus discussed here were calculated as the secant from the stress-strain relationship up to one third of the ultimate load.

Six prisms of each block-mortar combination were constructed, with three blocks and two $10 \mathrm{~mm}$ horizontal mortar joints. A total of 42 full-block prisms were tested axially normal to the bed face. Special care was taken to ensure constant height for all mortar joints. Table 1 summarizes the dimension of the block, the compressive strength of the block $f_{\mathrm{b}}$ in net area, the absorption of water in $24 \mathrm{~h}$ and the relation between net $A_{\text {net }}$ and gross $A_{\text {gross }}$ area. Table 2 summarizes the proportion in volume and the mean compressive strength of mortar $f_{\mathrm{m}}$ obtained in six samples. The strains have been calculated from the average displacement values measured at both sides of the prism, as shown in Fig. 3, meaning that each value represents the average of two readings. The model formulated by 

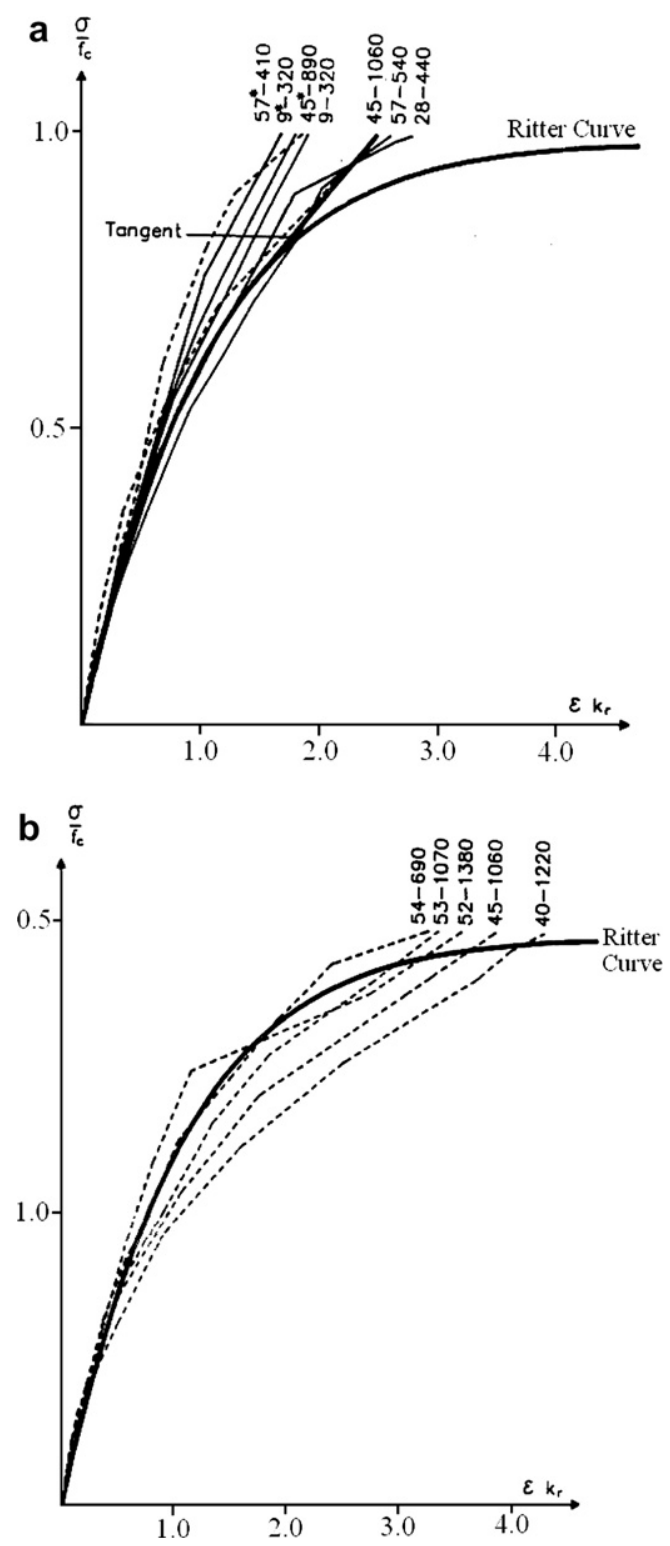

Fig. 2. Normalized stress-strain curve [3]: (a) standard cases; (b) hollow bricks with weak mortar. Notation $x x-y y y$ indicates brick strength and Ritter constant.

Table 1

Physical and mechanical characterization of block

\begin{tabular}{lllllll}
\hline Type & \multicolumn{2}{l}{ Block $(\mathrm{mm})$} & & $\begin{array}{l}f_{\mathrm{b}} \\
(\mathrm{MPa})\end{array}$ & $\begin{array}{l}\text { Water } \\
\text { absorption }(\%)\end{array}$ & $\begin{array}{l}A_{\text {net }} / \\
A_{\text {gross }}\end{array}$ \\
\cline { 2 - 4 } & Length & High & Thickness & & & \\
I & 390 & 190 & 140 & 18.2 & 6.8 & 0.58 \\
II & 390 & 190 & 140 & 27 & 6.4 & 0.58 \\
\hline
\end{tabular}

Knutson [3] and the experimental results obtained for the prisms made with mortars type 1:0.25:3 $\left(f_{\mathrm{m}}=19.9 \mathrm{MPa}\right)$, 1:0.5:4.5 $\left(f_{\mathrm{m}}=8.63 \mathrm{MPa}\right), 1: 1: 6\left(f_{\mathrm{m}}=4.2 \mathrm{MPa}\right)$ and 1:2:9 $\left(f_{\mathrm{m}}=2.9 \mathrm{MPa}\right)$ are considered for further analysis in Fig. 3.

Good agreement was found between the model shown in the previous section and the experimental results for mor-
Table 2

Types of mortar used in experimental tests

\begin{tabular}{lllll}
\hline Type & \multicolumn{2}{l}{ Mortar (in volume) } & $f_{\mathrm{m}}(\mathrm{MPa})$ \\
\cline { 2 - 4 } & Cement & Lime & Sand & \\
\hline I & 1 & 0.25 & 3 & 19.9 \\
II & 1 & 0.50 & 4.5 & 8.6 \\
III & 1 & 1 & 6 & 4.2 \\
IV & 1 & 2 & 9 & 2.9 \\
\hline
\end{tabular}

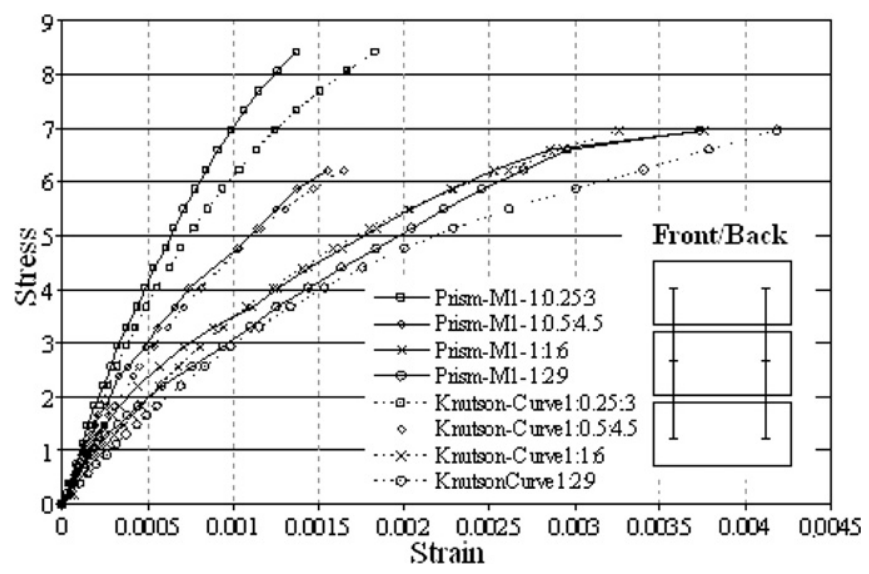

Fig. 3. Stress-strain diagrams for hollow concrete blocks masonry prisms $[8,9]$.

tars 1:0.5:4.5 and 1:1:6. For masonry prisms made using mortar type 1:0.25:3, the proposed model and the experimental results do not show good agreement for a stress level higher than $50 \%$ of the ultimate compressive strength of prisms. For mortar type 1:2:9, the non-linear behavior is even more severe and occurs at stress levels higher than $30 \%$ of the ultimate compressive strength of masonry.

Fig. 4 shows additional results with two different concrete blocks and different mortar strengths $[8,9]$. The arrow and number 1 indicate the onset of the inelastic response of the masonry prism, once the stress level reaches a value of $30 \%$ of the ultimate strength. It can be observed that the responses are similar in both prisms with significant inelastic deformation due to damage in the prism, caused by flaws and voids. It's well established that voids and flaws are sources of crack initiation. Therefore, it is possible to determine what combination of applied stress starts to produce bond-breaking stress.

The possibility to adopt another simplified mathematical expression for the stress-strain relationship is considered next. The hyperbolic function is adopted to determine the initial tangent modulus from stress-strain diagram of masonry as shown in Eq. (7). This proposal has been made originally by Kondner [14] to represent the non-linear behavior of cohesive soils. In this equation, $a$ and $b$ are constants, whose values need to be determined experimentally and whose graphical meaning is indicated in Fig. 5. Kondner [14] showed that the values of the coefficients $a$ and $b$ may be readily determined if the stress-strain data are plotted on the transformed axes shown in Figs. 6-9. Recasting 

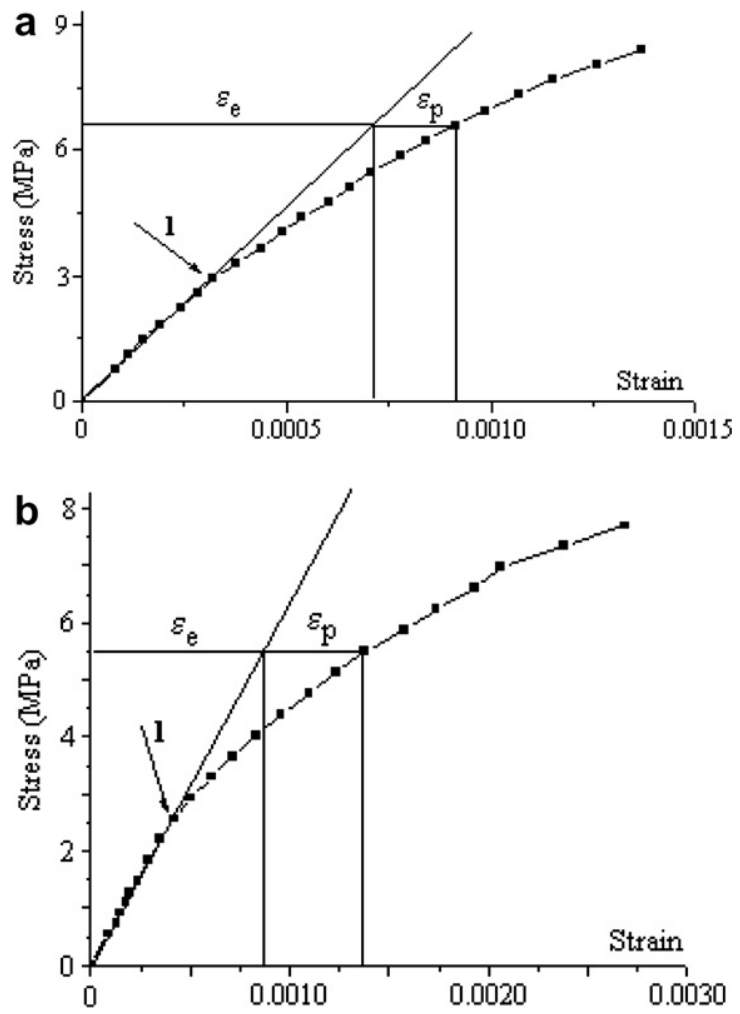

Fig. 4. Selected examples of stress-strain diagrams for different masonry prisms $[8,9]$ : (a) $f_{\mathrm{b}}=18.2 \mathrm{MPa}$ and mortar 1:0.25:3; (b) $f_{\mathrm{b}}=27 \mathrm{MPa}$ and mortar 1:1:6.

Eq. (7) as Eq. (8), constants $a$ and $b$ are, respectively, the interception with the vertical axes and the slope of the resulting straight line.

$\sigma=\frac{\varepsilon}{a+b \varepsilon}$
$\frac{\varepsilon}{\sigma}=a+b \varepsilon$

Figs. 6-9 present the linear correlations that best fit the different test data. As it is shown, the correlation coefficient $R^{2}$ is close to 1.0 , meaning that the agreement between the theoretical relation and the test data are excellent. Constants $a$ and $b$ were obtained from Eq. (8), where it is noted that $E_{0}$ is equal to $1 / a$. Fig. 10 plots the relation between

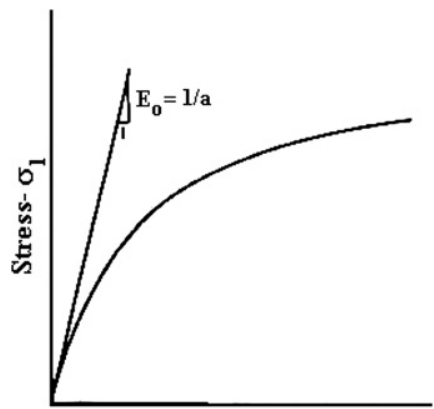

Axial Strain

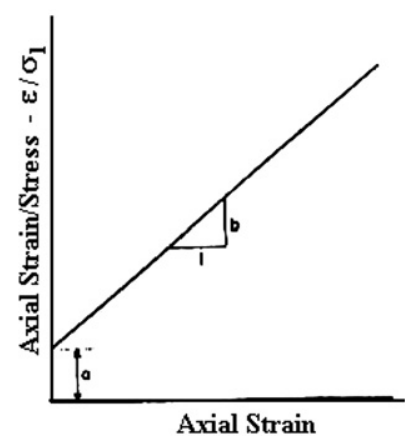

Fig. 5. Hyperbolic stress-strain curve and transformed hyperbolic stressstrain curve [14].

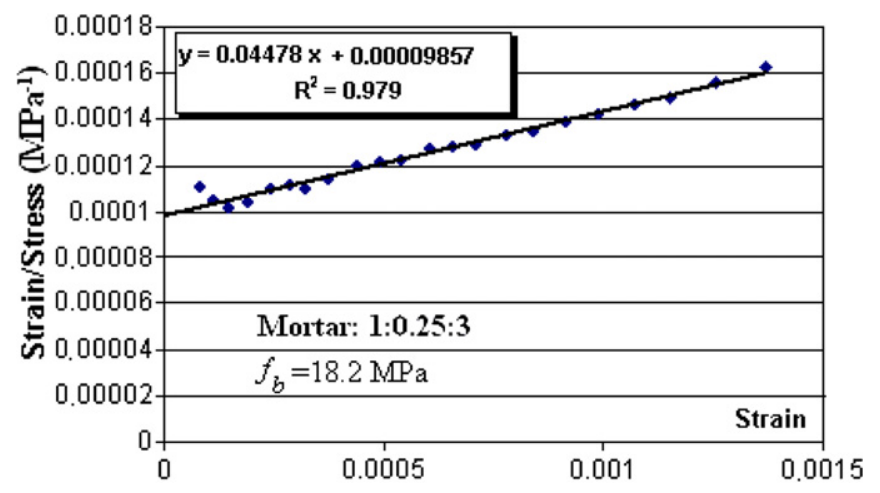

Fig. 6. Transformed hyperbolic curve for strong mortar prism.

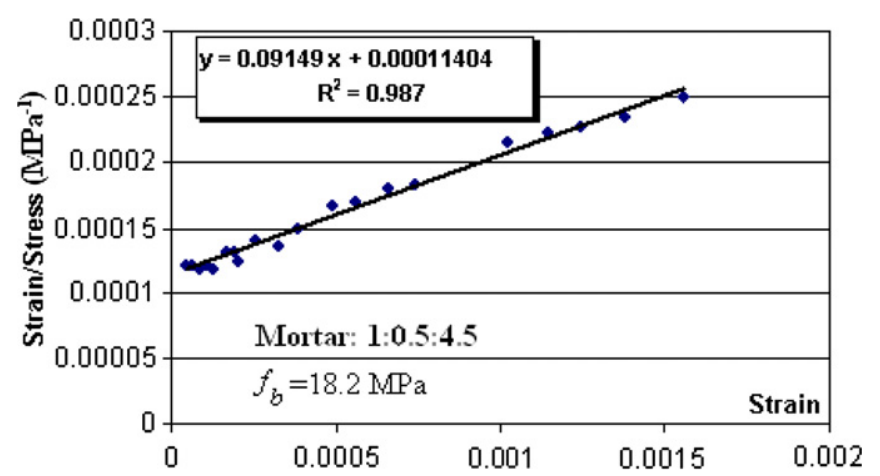

Fig. 7. Transformed hyperbolic curve for intermediate mortar prism.

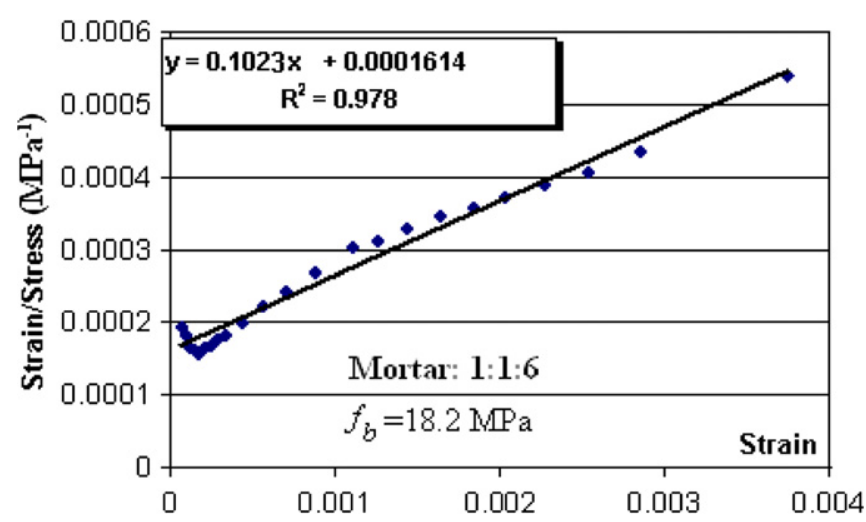

Fig. 8. Transformed hyperbolic curve for weak mortar prism.

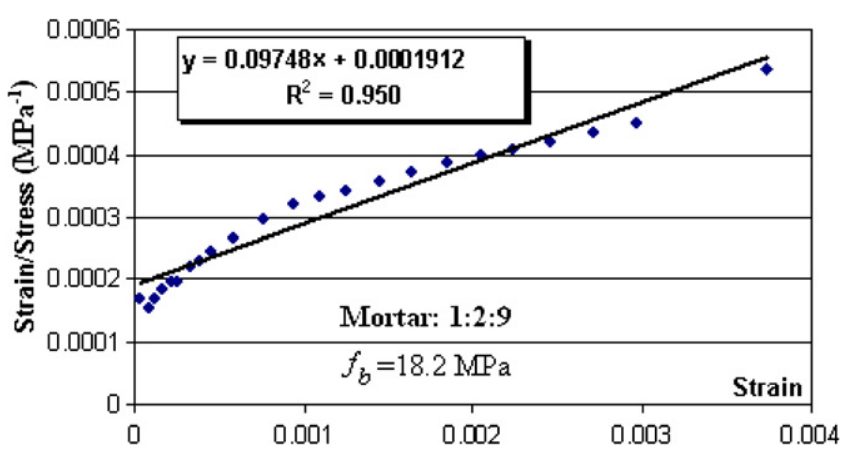

Fig. 9. Transformed hyperbolic curve for weak mortar prism. 


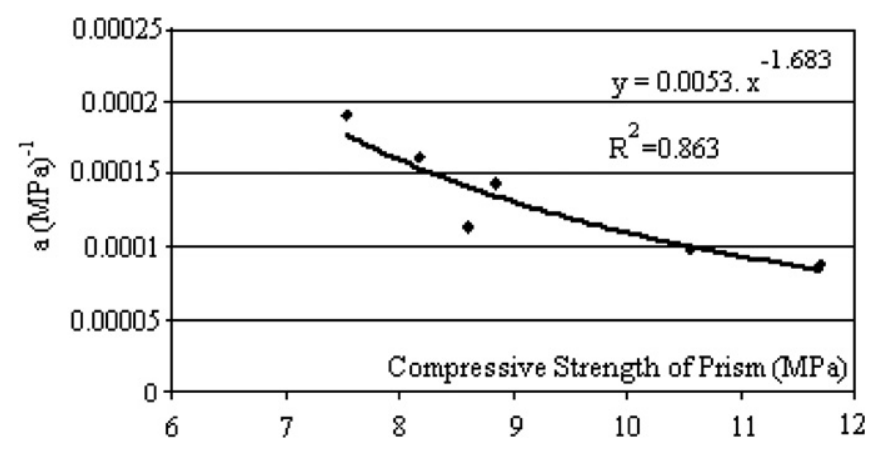

Fig. 10. Relationship between the constant $a(\mathrm{MPa})^{-1}$ and compressive strength of masonry.

constant $a(\mathrm{MPa})^{-1}$ and the masonry compressive strength. From this relation, it is straightforward to determinate the relation between the elasticity modulus of masonry and the compressive strength as:

$E_{0}=188 \cdot f_{\mathrm{c}}^{1.6853}$

Introducing Eq. (9) in Eqs. (5) and (6), it is possible to predict the trajectory of the full stress vs. strain relationship for the masonry. Notice that $\sigma / f_{\mathrm{c}}$ should be $<1$.

Table 3 presents the experimental results from prisms built using four types of mortars, and two strengths of blocks and the results of the proposed linearization. Here, $f_{\text {prism }}$ is the compressive strength of prisms measured in the full area; $E_{\text {mortar }}$ is the mortar elasticity modulus obtained from cylinder cast specimens, at a strain level corresponding to $30 \%$ of the uniaxial mortar strength $f_{\mathrm{m}}$; and $E_{0}$ is the initial tangent elasticity modulus obtained by linearization (Eq. (9)).

From the experimental tests, it can be concluded that the prisms built with mortar types 1:1:6 and 1:2:9 showed similar results in terms of initial tangent modulus $E_{0}$, as well as prisms built with mortar types 1:0.25:3 and 1:0.5:4.5. The tests indicate that the strength of the prism increases with the increase of the compressive strength of blocks, and with the increase in the compressive strength of mortar. It is also possible to conclude that uniaxial tests in mortar are not representative of the mortar bed joint, because no correlation is found between initial tangent modulus of the masonry prism $E_{0}$ and $E_{\text {mortar }}$.

In Table 4, the six cases studied experimentally are shown, indicating the block strength, relationship between

Table 3

Results obtained from linearization of stress vs. strain curve of concrete block prism

\begin{tabular}{lccccl}
\hline $\begin{array}{l}\text { Type of } \\
\text { mortar }\end{array}$ & $\begin{array}{c}f_{\text {prism }} \\
(\mathrm{MPa})\end{array}$ & $\begin{array}{c}f_{\mathrm{m}} \\
(\mathrm{MPa})\end{array}$ & $\begin{array}{c}E_{\text {mortar }} \\
(\mathrm{MPa})\end{array}$ & $\begin{array}{l}E_{0}=1 / a \\
(\mathrm{MPa})\end{array}$ & $\begin{array}{l}f_{\mathrm{b}} \\
(\mathrm{MPa})\end{array}$ \\
\hline $1: 0.25: 3$ & 10.56 & 19.9 & 11,230 & 10,145 & 18.2 \\
$1: 0.5: 4.5$ & 8.6 & 8.63 & 6409 & 8787 & 18.2 \\
$1: 1: 6$ & 8.17 & 4.2 & 4033 & 6197 & 18.2 \\
$1: 2: 9$ & 7.54 & 2.9 & 2042 & 5229 & 18.2 \\
$1: 0.25: 3$ & 11.7 & 19.2 & 11,055 & 11,330 & 27 \\
$1: 1: 6$ & 8.84 & 5.41 & 4527 & 6944 & 27 \\
\hline
\end{tabular}

Table 4

Results of strength blocks, relationship between initial tangent modulus $\left(E_{0}\right)$ and prism strength $\left(f_{\text {prism }}\right)$, mortar strength and Ritter constant

\begin{tabular}{lllccr}
\hline Case & Type of mortar & $f_{\mathrm{b}}(\mathrm{MPa})$ & $E_{0} / f_{\text {prism }}$ & $f_{\mathrm{m}}(\mathrm{MPa})$ & \multicolumn{1}{c}{$K r$} \\
\hline 1 & $1: 0.25: 3$ & 18.2 & $10,145 / 10.56$ & 19.9 & 960 \\
2 & $1: 0.5: 4.5$ & 18.2 & $8787 / 8.6$ & 8.63 & 1021 \\
3 & $1: 1: 6$ & 18.2 & $6197 / 8.17$ & 4.2 & 758 \\
4 & $1: 2: 9$ & 18.2 & $5229 / 7.54$ & 2.9 & 693 \\
5 & $1: 0.25: 3 *$ & 27 & $11,330 / 11.7$ & 19.2 & 968 \\
6 & $1: 1: 6 *$ & 27 & $6944 / 8.84$ & 5.41 & 785 \\
\hline
\end{tabular}

initial elasticity modulus and prism strength, mortar strength and the Ritter constant. The first conclusion is that the Ritter constant is not related to the strength of the block. For cases 1 and 5, the value was rather close, as well as for cases 3 and 6 . For hollow concrete block masonry with weak mortar types (cases 3, 4 and 6) the Ritter constant obtained was 0.7 of obtained for stronger mortar types (cases 1 and 5). This is in agreement with the conclusions of Knutson [3]. The results also show that an increase in the compressive strength of the block from 18.2 $\mathrm{MPa}$ to $27 \mathrm{MPa}$, using same mortar, does not change the Ritter constant significantly. This confirms that the non-linear response of the prism is mostly governed by the mortar bedding.

\section{Lateral deformation for the masonry composite}

It is widely accepted that failure of masonry is mostly governed by the difference in behavior of mortar and unit. The mortar, being usually softer and weaker than the units, is confined laterally, giving rise to lateral tension in the units and lateral compression in the mortar [15]. The results in hollow concrete block masonry prisms from $[8,9]$ are again discussed with respect to lateral deformation. The lateral deformation in the stack-bonded prisms was difficult to establish from the results because it started at different load levels and exhibited considerable scatter. Fig. 11 presents stress-axial strain and stress-lateral strain diagrams for selected block and mortar types. The first prism was constructed with block strength of $18.2 \mathrm{MPa}$ and mortar strength 19.9 MPa. The second prism was constructed with block strength $27 \mathrm{MPa}$ and mortar strength 5.4 MPa. The ultimate axial strains are rather distinct for the masonry types shown. For the weaker block masonry, the ultimate axial strain was $0.137 \%$ and for the stronger block masonry, the ultimate axial strain was almost the double $(0.27 \%)$. Nevertheless, the ultimate lateral strain was quite similar for the two cases, respectively, $0.059 \%$ and $0.063 \%$.

Fig. 12 shows the Poisson's ratio of the same masonry prisms, obtained by the division between lateral strain and axial strain. The large increase in the Poisson's ratio for the prisms built with mortar 1:0.25:3 occurs after a relative stress/strength value of 0.6 , with a Poisson's ratio near failure equal to 0.45 . For the prisms built with mortar type 1:1:6 the Poisson's ratio shows an increase during the entire relative stress/strength path, with a Poisson's ratio 


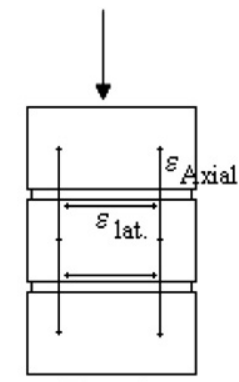

Front

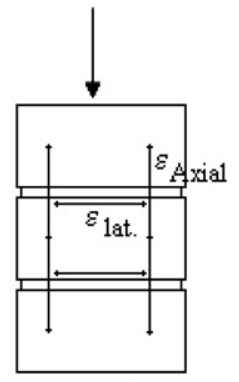

Back a

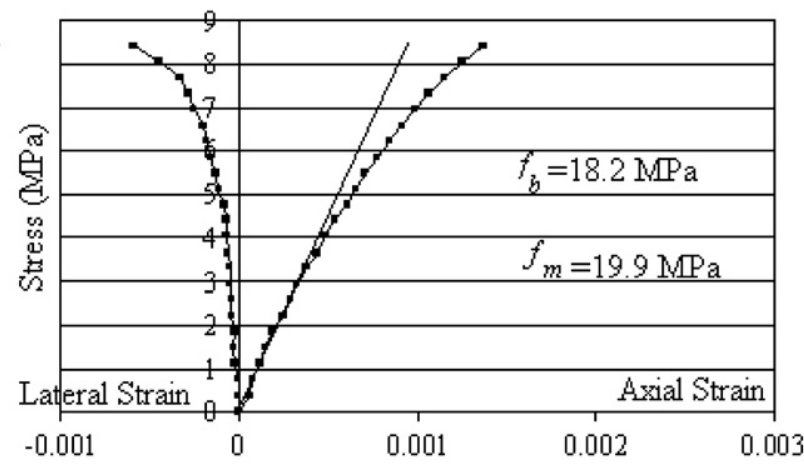

b

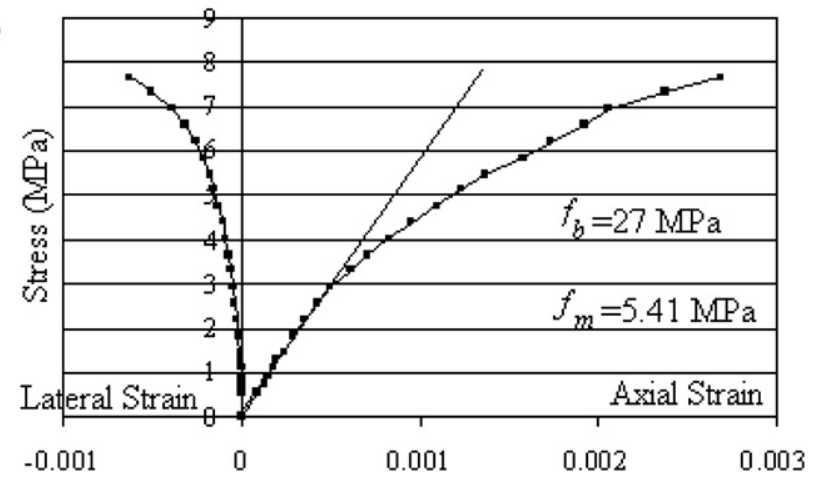

Fig. 11. Typical examples of stress-axial strain diagram and stress-lateral strain diagram: (a) mortar 1:0.25:3; (b) mortar 1:1:6.

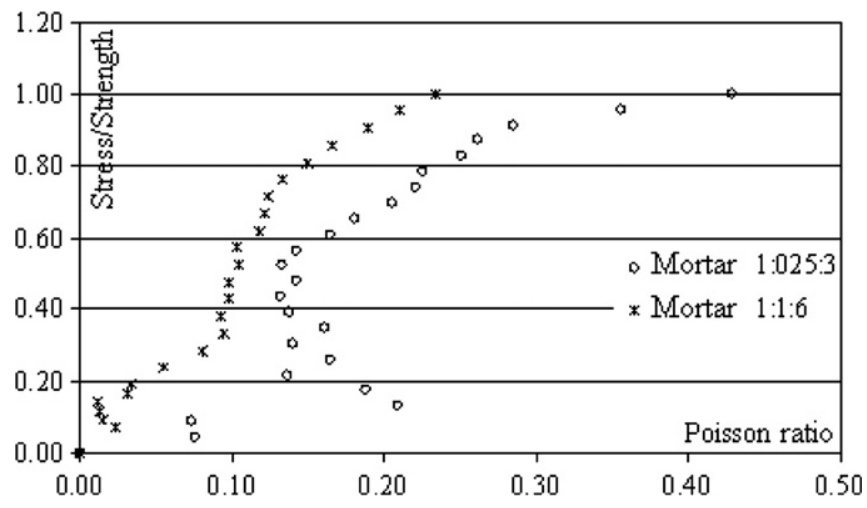

Fig. 12. Typical relation between stress/strength ratio and Poisson's ratio.

near at failure only equal to 0.25 . This indicates that it is necessary to account for the possible failure modes, in order to understand the mechanics of hollow concrete block masonry under compression.

\section{Failure modes for the masonry composite}

The tests carried out clearly indicate different failure modes of the masonry prisms according to the mortar type. For stronger mortars (type 1:0.25:3) the cracks appeared more localized, whereas for weaker mortars (type 1:1:6) the cracks in the hollow concrete block appeared dispersed. For stronger mortars, it seems that tensile stresses are induced in the block, leading to vertical cracks, see Fig. 13a. For weak mortars, spalling of the concrete block occurs close to the mortar joints, indicating a possible crushing of the mortar, see Fig. 13b. Mortar crushing leads to tensile cracks in the block shells and not really a loss of strength of the composite.

Visual inspection of the mortar joint after collapse indicates that the mortar is still bonded to the lower block, with bond loss and mortar crushing only at the upper part of the joint, see Fig. 14. The possible reasons for this phenomenon are a lower porosity and lower bond between mortar and
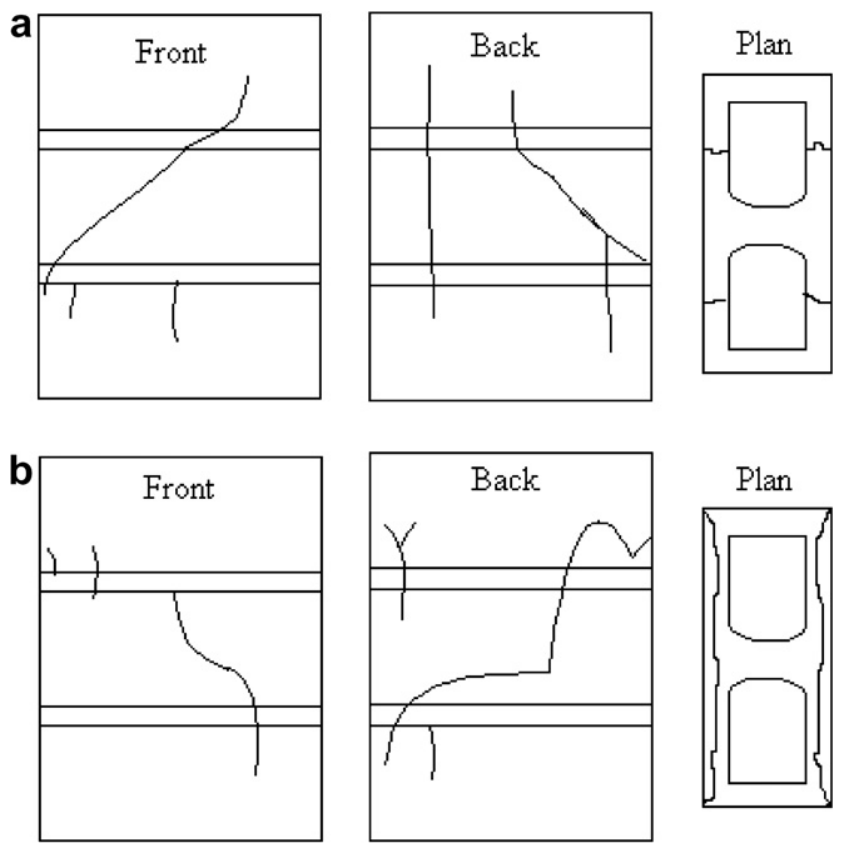

Fig. 13. Failure modes for hollow concrete masonry prisms: (a) strong mortar; (b) weak mortar.

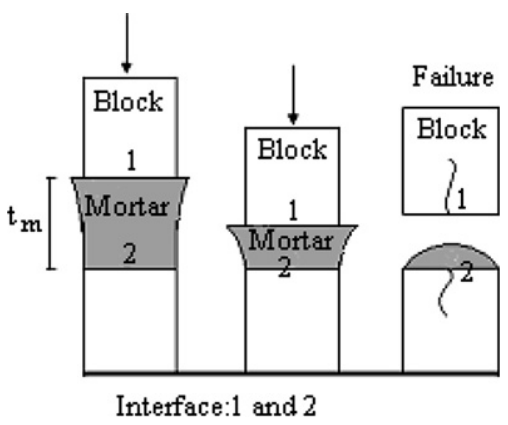

Fig. 14. Visually observed failure sequence for standard moderate and weak mortars. 

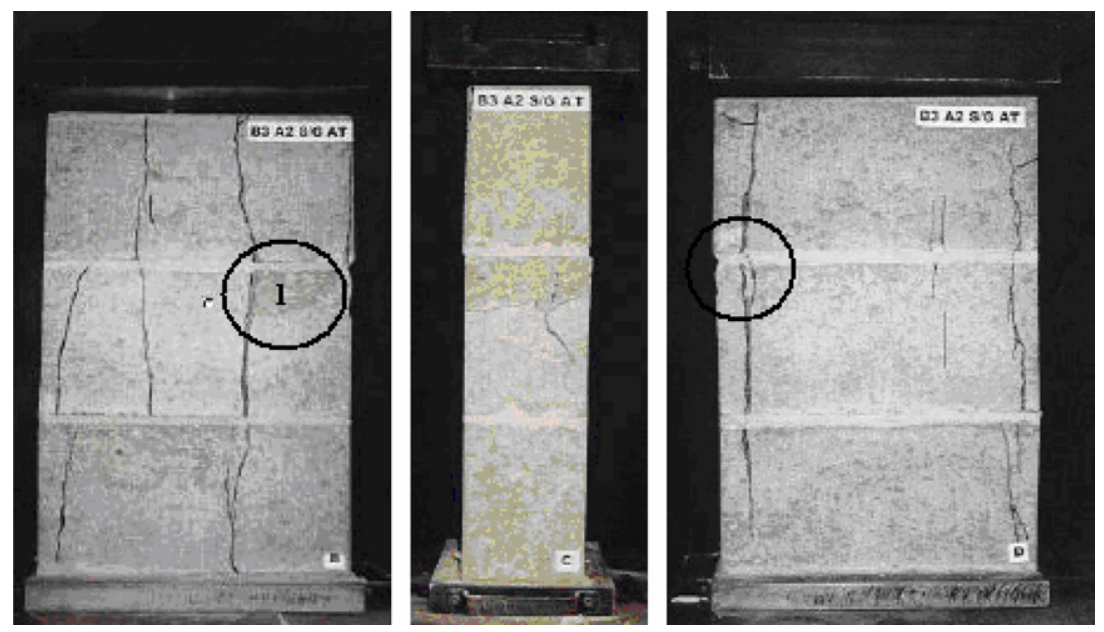

Fig. 15. Observed failure modes for hollow concrete block prisms [17].

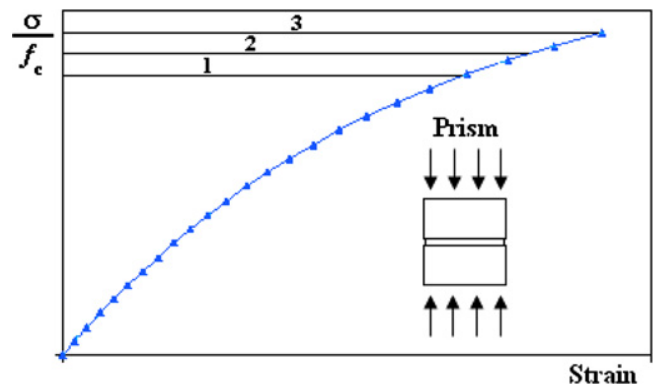

Fig. 16. Simplified model for failure phases in hollow concrete block.

unit at the upper part of the mortar to the bleeding. Similar phenomenon was found in Hamid and Drysdale [16].

Khalaf [5] analyzed the failure mode in hollow concrete block masonry prisms and found separation between all faces of the masonry unit. Fig. 15 shows the results of Romagna [17], where vertical cracks are visible in the connection between shells and webs. Nevertheless, also spalling of the block shell is found at selected regions (circled areas). This local collapse is associated with a loss of bearing capacity of the mortar with cracks parallel to the loading direction inside the block shell and along the longitudinal direction of the block. Fig. 16 presents a qualitative model of this failure mode observed in the tests, with three different phases. In phase 1, the loss of cohesion in the mortar is initiated. In phase 2, the mortar joint crushes and, in phase 3, the masonry shells spalls. The experimental results indicate that the ultimate strength of the masonry prism is only reached after phase 3 , meaning that a combination of mortar crushing and unit failure in tension is responsible for the failure. This also means that understanding the collapse of hollow concrete block masonry requires an adequate Poisson's ratio model for mortar.

\section{Tentative model for effective Poisson's ratio of mortar}

Describing the volumetric change of a material during loading is a difficult task due the variability of results, and the complexity inherent to the experiments and data acquisition. But a model for the Poisson's ratio is a must in the case confined behavior, such as the one described above. Khoo [18], Atkinson et al. [2] and Mohamad $[8,10]$ carried out a series of tests on mortar samples in a state of triaxial compression and concluded that a decrease in the Poisson's ratio can be found. Apparently this reduction was exponential for 1:1:6 and 1:2:9 mortars type and linear for 1:0.25:3 and 1:0.5:4.5 mortars. As shown in Khoo [18], Atkinson et al. [2] and Mohamad [8,10], the failure of masonry prisms in compression is caused by the initiation and propagation of cracks, which starts often induced by the mortar. Mortar exhibits high porosity and different sizes of voids, with a possible initial decrease in volume caused by closing of flaw and voids. Afterwards, the Poisson's ratio increases significantly until failure. The mortar consists of components that are bonded together. Therefore, an interface can be recognized between paste and grain. In concrete, the transition zone between grain and cement-paste is also the most porous component and can be considered as a weak link, Vermeltfoort [7].

The cohesive strength of masonry should be analyzed in the perspective of two competing failure modes: (a) the loss of adhesion between the interfaces of materials; and (b) the pore-collapse of internal structure caused by crushing of mortar. The knowledge of the configuration and distribution of internal mortar structures are still scarce. Diamond [19] presented an investigation using scanning electronic microscopy carried out in 28 day old mortars of sand contents in excess of $48 \%$ by volume. Fig. 17 shows the mortar surface under two levels of magnification. It is possible to observe the uniform gray sand grains (A), the extensive areas of bright, dense hardened cement paste (B) and the smaller areas of pores, darker hardened cement paste (C). Pore sizes up to $15 \mu \mathrm{m}$ in length can be found and most of the large pores appear to be interconnected.

A recent investigation using scanning electronic microscopy carried out in different types of mortar demonstrates that the high porosity of mortar can be responsible for 
a

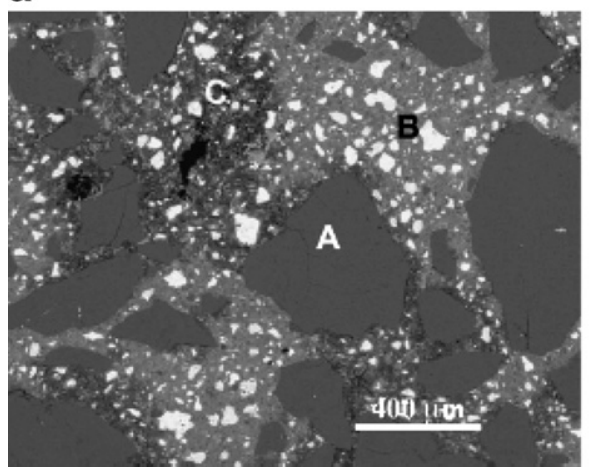

b

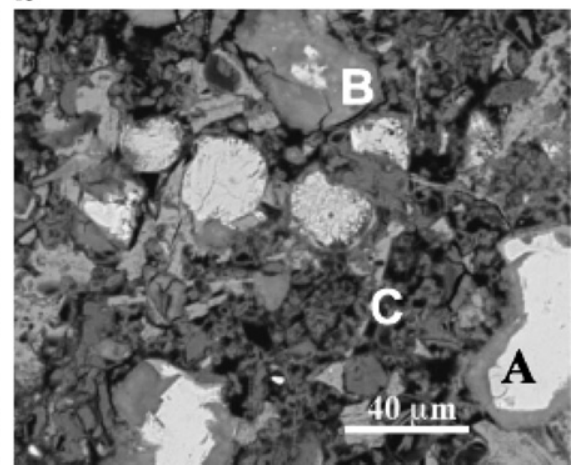

Fig. 17. Photos of scanning electronic microscopy obtained in mortar by Diamond [19]: (a) Low magnification; (b) High magnification.

changes in the mechanical properties, such as elasticity modulus and Poisson's ratio (Figs. 18 and 19). Fig. 18 shows images of mortar with different magnification, $40 \times$ (a), $200 \times$ (b) and $500 \times$ (c). Fig. 18 a shows the mortar surface obtained through a small broken part of mortar. It also shows the smooth surface generated through pull out of sand grains and the porous area is delimited by circles. Fig. 18b shows the small pores surrounding de macropores with dispersed cracks in the transition zone between paste and grain. The crack seems to be induced by shrinkage. The porosity of mortar depends on the composition, water/cement ratio, maximum diameter of sand and grain size distribution of the sand. Fig. 18a-c illustrate the porosity present in different locations of the same mortar. Macro-pores were found in the contact between paste and sand. Fig. 19 shows images of mortar with different magnification, $1000 \times(a), 1900 \times(b)$ and $5000 \times(c)$. As seen in these images, the pores are not isolated from each other and appear to be linked. Also it is easy to observe the result of internal C-S-H hydration. The typical large sizes of the pores and the interconnection can be observed in Fig. 19.

The compression tests were carried out in cylindrical specimens using a triaxial cell for testing properties of rock. The sizes of the specimens were $100 \mathrm{~mm} \times 200 \mathrm{~mm}$ and different level of confined pressure was applied. Mechanical properties under confined stress obtained from experimental tests shows a decrease in Poisson ratio of mortar under triaxial compression. The envelope failure of confined mortar obtained from different authors are given in Tables 5-7 $[2,8,10,18]$. Table 8 shows also the results of Poisson ratio under triaxial compression. The pore-collapse phenomenon seems a reasonable explanation for the decrease of Poisson's ratio with increasing lateral stress, for weak mortar such as 1:1:6 and 1:2:9 types.

Triaxial tests have been carried out by Hayen et al. [20] in historical mortar made using putty lime mortar, hydraulic lime mortar and lime-cement mortar. The relation between horizontal stress and vertical stress $(k)$ had changed throughout the test, with a $k$ ratio of $0,0.05,0.10$, $0.15,0.25,0.5,0.75$ and 1 . The pore structure of mortar during testing was measured by total pore volume through vacuum submersion, by means of mercury intrusion and by scanning electronic microscopy. The multiaxial stress analyses by Hayen et al. [20] lead to the following conclusions: (a) for $k<0.25$ shear failure mechanisms occur, with a decrease in volume of specimens, probably due to the internal closing of existing cracks and flaws. After the initial decrease, an increase in volume was observed, where shear bands develop. The collapse of mortar sample occurs along diagonal shears bands; (b) for $k \geqslant 0.25$, the failure mechanisms in mortar samples are rather distinct and were characterized by continuous decrease in volume of the samples. With this evidence it is possible to conclude that porecollapse occurs at $k \geqslant 0.25$.

A constitutive model to represent the non-linear elasticity of concrete was proposed by Ottosen [21]. The model consists in establishing phases for the Poisson's ratio as a function of the non-linearity rate namely $\beta$ (stress vs. strength ratio). The initial Poisson's ratio is constant until reaching $\beta_{1}$, which leads to a significant increase in the Poisson's ratio once failure occurs, as show in Fig. 20. In high strength concrete (60-120 MPa), the lateral stress does not have a large influence in Poisson's until failure occurs because the lateral stress reached only $10-20 \%$ of ultimate strength and this is insufficient to modify the Poisson's ratio. The equations that represent the Poisson's ratio behavior proposed by Ottosen [21] are given by

$v_{a}=v_{i}^{a} \quad$ if $\beta \leqslant \beta_{1}$,

$v^{a}=v_{f}^{a}-\left(v_{f}^{a}-v_{i}^{a}\right) \cdot \sqrt{1-\left(\frac{\beta-\beta_{1}}{1-\beta_{1}}\right)} \quad$ if $\beta>\beta_{1}$

The mortar strength used on blocks bedding is usually much lower than concrete and depends from unit types. The strength levels of mortar are usually in the range of 2-10 MPa, meaning that the lateral stress increase can reach a value between $50 \%$ and $100 \%$ of the ultimate strength of the specimen. The experimental tests in mortar $[2,8,10,18]$ require an extended Ottosen model [21] to represent the possible modifications of Poisson's ratio, as shown in Fig. 21. For moderate strength mortars, the Poisson's ratio decreases until reaching $\beta_{1}$ and then gently increases 

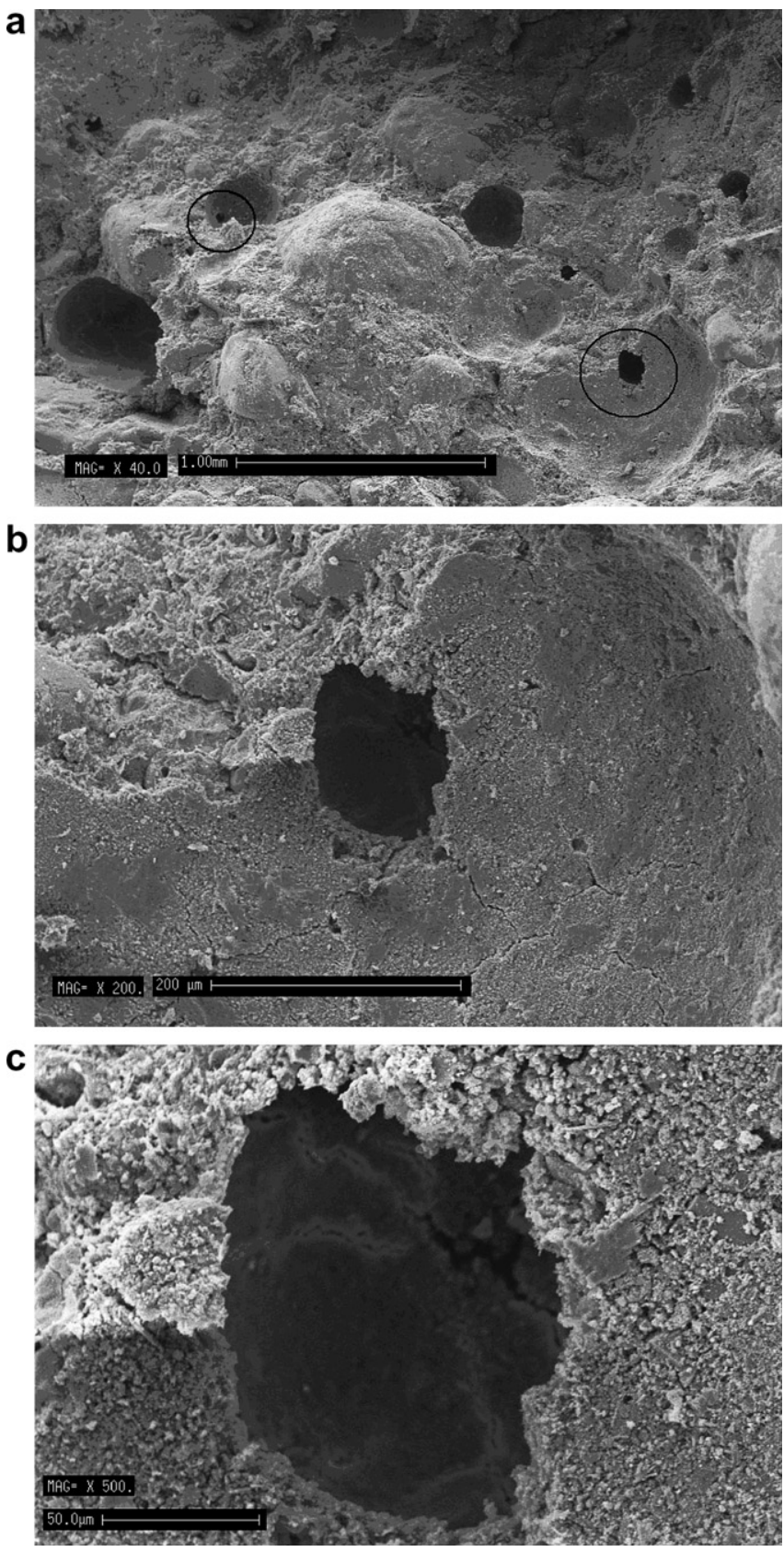

Fig. 18. Photos of scanning electronic microscopy in mortar: (a) 40x; (b) 200x; (c) $500 \times$.

until collapse, with a shear failure mechanism developing. For weak mortars, the Poisson's ratio decreases until reaching $\beta_{1}$ and then increases swiftly due the porecollapse, cohesive loss of grains and closing of cracks. The cohesive loss of mortar arises suddenly and increases the tensile stress in the unit. The dashed lines in these graphs represent an extension of the Ottosen model, depending on characteristics such as mortar porosity and cement contents. Validation of the authors' proposal against experimental results is required. This calls for additional experimental results on triaxial mortar samples under deformation control, using novel testing equipments.
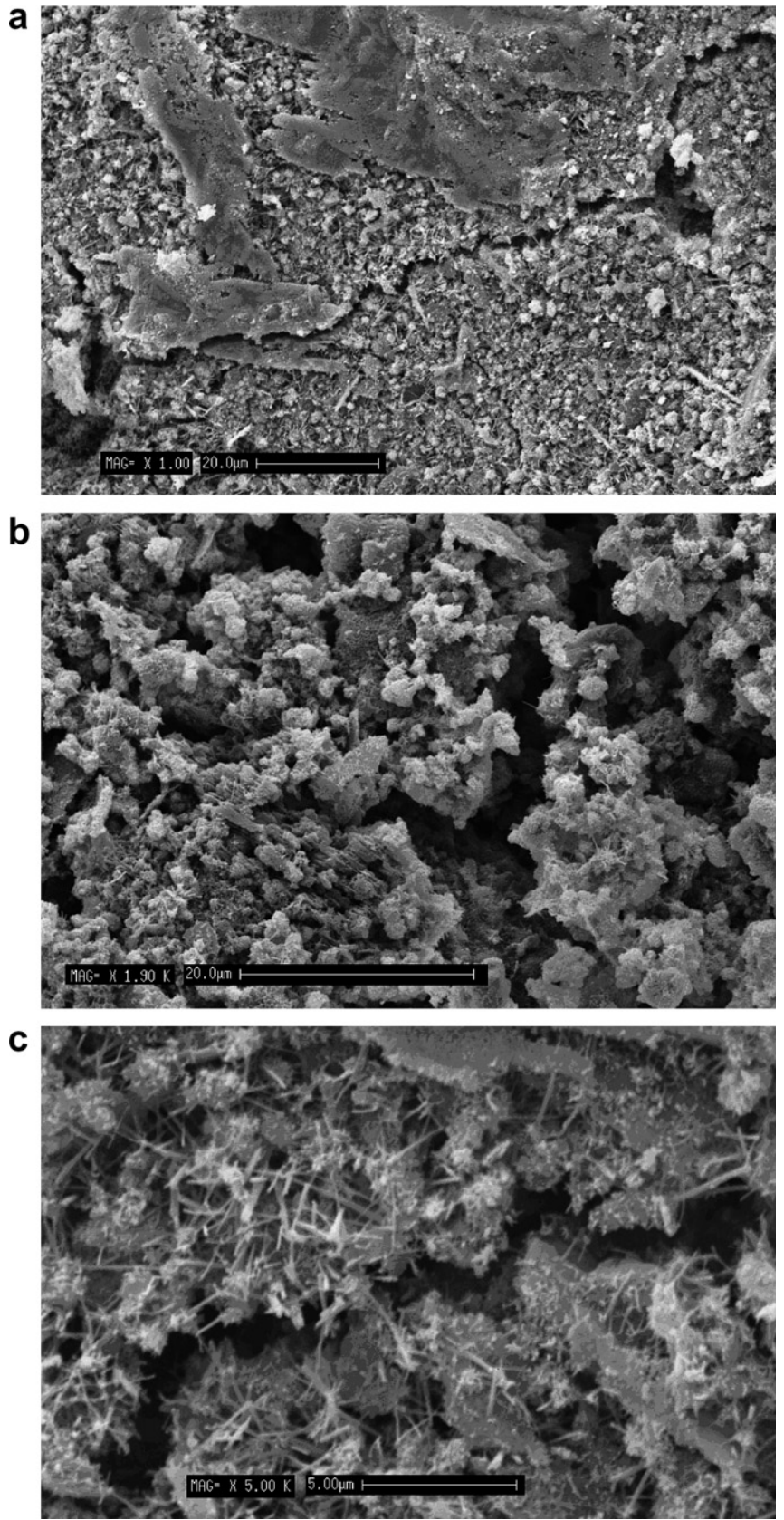

Fig. 19. Photos of scanning electronic microscopy in mortar: (a) $1000 \times$ (b) $1900 \times$; (c) $5000 \times$

Proposed equations for Fig. 21 are given by (diagram a)

$$
\begin{aligned}
& v^{a}=\left(v_{i}^{a}\right) \cdot \mathrm{e}^{-\beta} \quad \text { if } \beta \leqslant \beta_{1}, \\
& v^{a}=v_{f}^{a}-\left(v_{f}^{a}-v_{i}^{a}\right) \cdot \sqrt{1-\left(\frac{\beta-\beta_{1}}{1-\beta_{1}}\right)} \quad \text { If } \beta>\beta_{1}
\end{aligned}
$$

and by (diagram b)

$$
\begin{aligned}
& v^{a}=\left(v_{i}^{a}\right) \cdot \mathrm{e}^{-\beta} \quad \text { if } \beta \leqslant \beta_{1}, \\
& v^{a}=\left(v_{i}^{a}\right) \cdot \mathrm{e}^{\beta} \quad \text { if } \beta>\beta_{1}
\end{aligned}
$$


Table 5

Envelope failure of mortar (Khoo [18])

\begin{tabular}{ll}
\hline Mortar-type & Envelope of failure \\
\hline $1: 0.25: 3$ & $f_{\mathrm{m}}^{*}=f_{\mathrm{m}}+3.4 \sigma_{3}$ \\
$1: 1: 6$ & $f_{\mathrm{m}}^{*}=f_{\mathrm{m}}+2.3 \sigma_{3}$ \\
\hline
\end{tabular}

Table 6

Envelope failure of mortar (Atkinson et al. [2])

\begin{tabular}{ll}
\hline Mortar-Type & Envelope of failure \\
\hline $1: 0.25: 3$ & $f_{\mathrm{m}}^{*}=f_{\mathrm{m}}+5 \sigma_{3}$ \\
$1: 0.5: 4.5$ & $f_{\mathrm{m}}^{*}=f_{\mathrm{m}}+3 \sigma_{3}$ \\
$1: 1: 6$ & $f_{\mathrm{m}}^{*}=f_{\mathrm{m}}+2 \sigma_{3}$ \\
$1: 2: 9$ & $f_{\mathrm{m}}^{*}=f_{\mathrm{m}}+2 \sigma_{3}$ \\
\hline
\end{tabular}

Table 7

Envelope failure of mortar (Mohamad [8,10])

\begin{tabular}{ll}
\hline Mortar-type & Envelope of failure \\
\hline $1: 0.25: 3$ & $f_{\mathrm{m}}^{*}=f_{\mathrm{m}}+4 \sigma_{3}$ \\
$1: 0.5: 4.5$ & $f_{\mathrm{m}}^{*}=f_{\mathrm{m}}+3.6 \sigma_{3}$ \\
$1: 1: 6$ & $f_{\mathrm{m}}^{*}=f_{\mathrm{m}}+2.6 \sigma_{3}$ \\
$1: 2: 9$ & $f_{\mathrm{m}}^{*}=f_{\mathrm{m}}+2.5 \sigma_{3}$ \\
\hline
\end{tabular}

Table 8

Poisson ratio of confined mortar (Mohamad $[8,10])$

\begin{tabular}{llll}
\hline Type & Lateral stress & Poisson ratio \\
\cline { 3 - 4 } & & Initial stress level & Ultimate stress level \\
\hline $1: 0.25: 3$ & $0,0.5,1$ & 0.20 & 0.20 \\
& 2.5 & 0.10 & 0.10 \\
$1: 0.5: 4.5$ & 0 & 0.10 & 0.14 \\
& 1 & 0.13 & 0.17 \\
& 2.5 & 0.09 & 0.24 \\
$1: 1: 6$ & 0 & 0.10 & 0.37 \\
& 0.5 & 0.07 & 0.11 \\
& 2.5 & 0.05 & 0.09 \\
& 4 & 0.02 & 0.09 \\
$1: 1: 6$ & 0 & 0.17 & 0.14 \\
& 0.5 & 0.04 & 0.17 \\
& 1 & 0.05 & 0.07 \\
\hline
\end{tabular}

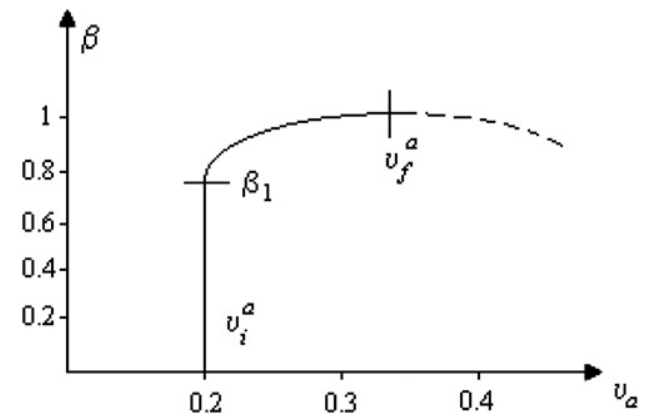

Fig. 20. Poisson's ratio behavior proposed by Ottosen [21].

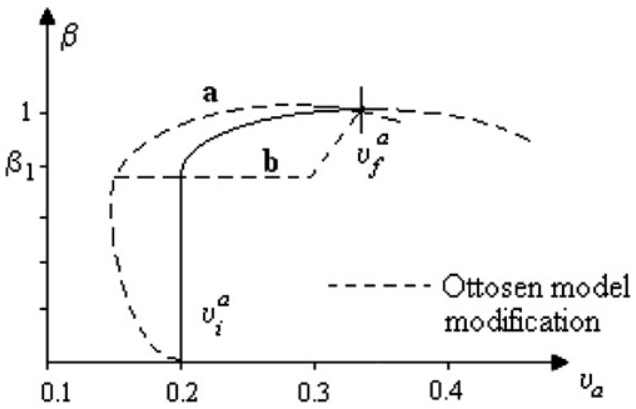

Fig. 21. The modification of Ottosen [21] model (dashed line).

\section{Conclusions}

The main conclusions of the present study are the following:

- Mortar governs the non-linear behavior of masonry.

- The small diameter pores or micropores are produced due to the structural arrangement between binder and sand, whereas the macropores occur due to phenomenon such as bleeding, that generate water accumulation on the surface of sands.

- A large influence of the type of mortar in the axial strain of masonry prisms was observed.

- The failure mode of prisms built with mortar 1:0.25:3 are symmetric, vertical and scattered, whilst on the prisms built with mortar 1:0.5:4.5 a combination of vertical cracks and localized crushing was noticed.

- On the prisms built with mortar 1:0.5:4.5, localized crushing induces considerable tensile stresses in the block.

- A polynomial expression is the best fit curve between the elasticity modulus and the compressive strength of masonry. This demonstrates that there is a non-linear relation between strength and the elasticity modulus.

- There is clear evidence that the elasticity modulus of mortar measurements from cylinders is very distinct from bed joint actual behavior.

- The failure mode of hollow concrete block masonry depends on the mortar type.

- The Poisson's ratio near failure of masonry prisms is strongly dependent on the mortar type.

Further studies are needed to determine the mechanical behavior of mortar in the joint and to understand the failure mechanism of masonry under compression. In particular, tests on mortar collected from actual samples in the joints, scanning electronic microscopy and triaxial testing of mortar are needed.

\section{Acknowledgement}

The author thank the "Coordenação de Aperfeiçoamento de Pessoal de Nível Superior" (CAPES) for the financial support. 


\section{References}

[1] CEN. Eurocode 6: Design of masonry structures - Part 1 - Common rules for reinforced and unreinforced masonry structures. EN-1996-1$1 ; 2005$.

[2] Atkinson RH, Noland JL, Abrams DP, McNary S. A deformation failure theory for stack-bond brick masonry prisms in compression. In: Proceedings 3rd NAMC 1985, Arlington. p. 18_1-18.

[3] Knutson HH. The stress-strain relationship for masonry. Masonry Int 1993;7(1):31-3.

[4] Cheema TS, Klingner RE. Compressive strength of concrete masonry prisms. American Concrete Institute. ACI Struct J 1986;83(1):88-97. January-February.

[5] Khalaf FM. Factors influencing compressive strength of concrete masonry prisms. Mag Concrete Res 1996;48(175):95-101. June.

[6] Khalaf FM, Hendry AW, Fairbairn DR. Study of the compressive strength of blockwork masonry. Struct J, ACI 1994;94(4):365-75.

[7] Vermeltfoort, AT. Brick-mortar interaction in masonry under pressure, PhD thesis, October; 2004.

[8] Mohamad G. Comportamento mecânico na ruptura de prismas de bloco de concreto à compressão, MSc thesis. Federal University of Santa Catarina, Florianópolis, Brazil; 1998 [in Portuguese].

[9] Mohamad G, Roman HR. Compressive strength of mortars under triaxial compression. In: Proceedings of British Masonry Society, October; 1998. p. 100-2.

[10] Mohamad G, Lourenço PB, Roman HR. Mechanical behaviour assessment of concrete block masonry prisms under compression. In: International conference on concrete for structures (INCOS); 2005. p. 261-8.
[11] ASTM C-270: American society for testing and materials (ASTM) ASTM C-270: Standard specification for mortar for unit masonry. Pennsylvania; 1997.

[12] BSI 5628: British standards institution (BSI). BSI-5628: Structural use of unreinforced masonry. London, Part 1; 1992.

[13] NBR 13279: Brazilian standard (NBR). NBR-13279: ArgamassaDeterminação da resistência à compressão- Método de ensaio, Rio de Janeiro; 1995.

[14] Kondner RL. Hyperbolic stress-strain response: cohesive soils. J Soil Mech Found Div, ASCE 1963;89(1):115-43.

[15] Shrive NG. The failure mechanism of face-shell bedded (ungrouted and unreinforced) masonry. Int $\mathbf{J}$ Masonry Construct 1982;2(3):115-27.

[16] Hamid AA, Drysdale RG. Behavior of concrete block masonry under axial compression. J Am Concrete Struct 1979;76(6):707-21.

[17] Romagna RH. Resistência à compressão de prismas de blocos de concreto grauteados e não-grauteados. MSc Thesis. Federal University of Santa Catarina, Florianópolis, Brazil; 2000 [in Portuguese].

[18] Khoo CL. A failure criterion for brickwork in axial compression, PhD Thesis. Edinburgh, Scotland, University of Edinburgh; 1972.

[19] Diamond S. Percolation due to overlapping ITZs in laboratory mortars? A microstructural evaluation. Cement Concrete Res 2003;33:949-55.

[20] Hayen R, Van Balen K, Van Gemert D. The mechanical behaviour of mortars in triaxial compression. In: Proceedings of structural analysis of historical construction, Modena, Lourenço \& Roca; 2005. p. 6117.

[21] Ottosen NS. Constitutive model for short-time loading of concrete. J Eng Mech Div ASCE 1979;105(2):127-41. 